\title{
A Qualitative Study on The Motives for Information Gathering and Use of Health Food Substance Pueraria Mirifica In Japan
}

\author{
Keiko Yukawa ${ }^{1 *}$, Tomoko Kodama ${ }^{2}$, Mayumi Fujiki ${ }^{3}$, Junko Sasaki ${ }^{3}$, Yuka Koizumi ${ }^{3}$, Ichiro Arai ${ }^{4}$ \\ and Hitoshi Fujii ${ }^{3}$ \\ ${ }^{1}$ Department of Health Policy and Technology Assessment, National Institute of Public Health, Japan \\ ${ }^{2}$ Department of International Health and Collaborations, National Institution of Public Health, Japan \\ ${ }^{3}$ Department of Nursing, Mejiro University, Japan
}

${ }^{4}$ Department of Pharmaceutical Sciences, Nihon Pharmaceutical University, Japan

*Corresponding author: Keiko Yukawa, Senior Researcher, Department of Health Policy and Technology Assessment, National Institute of Public Health, 2-3-6, Minami, Wako-shi, Saitama, 351-0197, Japan

\section{ARTICLE INFO}

Received: 豐 December 17, 2020

Published: 蔧 December 23, 2020

Citation: Keiko Yukawa, Tomoko Kodama, Mayumi Fujiki, Junko Sasaki, Yuka Koizumi, Ichiro Arai, Hitoshi Fujii. A Qualitative Study on The Motives for Information Gathering and Use of Health Food Substance Pueraria Mirifica In Japan. Biomed J Sci \& Tech Res 32(5)-2020. BJSTR. MS.ID.005315.

Keywords: Qualitative Study, Health Food Female Hormone, Pueraria Mirifica, Japan

\section{ABSTRACT}

Objective: We aimed to determine the motives for Pueraria mirifica use in Japan.

Methods: We conducted a survey regarding health food use in March 2019. Kantoregion residents who had used health foods were recruited through a monitoring company and interviewed separately.

Results: The study included 14 females (mean age: 43.4 years). All had used Pueraria mirifica, and most expected a breast-enhancement effect. Most discovered the product online or by word-of-mouth. One participant required treatment for menstrual irregularity and breast tightness/discomfort after ingesting Pueraria mirifica.

Conclusion: Consumers often stop ingesting Pueraria mirifica due to poor health or after learning of the public alert. We must establish an information distribution system so that health food consumers have access to alert information before purchasing.

\section{Introduction}

In recent years, so-called "health foods" have caused health damages and have been circulated without legal restrictions. It has been reported that soy infravon is a female hormone-like agent that is effective against osteoporosis and menopause [1]. Pueraria mirifica has the effect of promoting oestrogen secretion [1]. It contains phytoestrogens and reportedly improved menopausal symptoms in a clinical trial. It has also been shown that phytoestrogens in Pueraria mirifica improve dyslipidaemia in postmenopausal women [1]. Health damages related to its consumption have been reported in individuals ranging widely in age (from teens to 50s); however, details regarding consumer behaviour remain unclear. In this study, we aimed to discover the motivations for use, the methods of information gathering, and the characteristics of Pueraria mirifica use. Because there had been health damages caused by so-called "health foods" and no legal restrictions were in place, the government revised the Food Sanitation Act in 2018 to ensure the safety of raw materials used in health foods, to collect health damage information, and to examine the responses to the health damages.

The government has been attempting to establish a system to encourage the distribution of appropriate information among consumers and businesses. However, the information and intentions on which health food purchases are based remain unknown. Therefore, we sought to examine the factors surrounding 
the use of health foods that have caused health damages in the past and for which alerts have been issued. Food items that have caused health damages include Pueraria mirifica and black cohosh for body shaping and snow tea and amebasiba for weight loss. In particular, the Japanese government has issued an alert for Pueraria mirifica $[1,2]$, and health hazards have been reported [1]. In this study, we aimed to clarify the situations surrounding the purchase of these health foods on the internet without a prescription or doctors' instructions. We hope to utilize this information in support of the effective dissemination of information and improvement of the Japanese government's food safety measures.

\section{Methods}

\section{Survey on Purchasing Motives and use of Health Foods}

We conducted an interview survey on the use of health foods such as Pueraria mirifica in March 2019. Individuals living in the Kanto area who had used Pueraria mirifica were recruited through a monitoring company and interviewed individually. The survey items included basic attributes (sex, age, educational background, health status) and the motives for purchasing the health foods (e.g. anxiety about health, content of advertisements, information sources). We gathered information using a simple questionnaire and asked specific questions in an approximately 30-minute interview about the purchase and ingestion of the health food. Interviews were recorded, and fieldnotes were created. We carefully examined the transcripts and classified the answers after considering the participant's overall meanings using the method put forth by Lofland et al. [2]. Peer examination was conducted among the investigators to improve the validity of the results.

\section{Ethical Considerations}

This study was approved by the ethics committee at Nihon Pharmaceutical University (Approval number: Japan Pharmaceutical Ethics 30-7). To protect the human rights and privacy of the study subjects, we received the survey results from a monitoring company using a form that did not include personal information. Written informed consent was obtained from all participants.

\section{Results}

\section{Subject Attributes}

The study included 14 women with a mean age of 43.4 years. More than $90 \%$ of the subjects answered that they were normally in very good health (Table 1). In one case, the subject experienced changes in her physical condition, including menstrual irregularity and tightness and discomfort of the breast [3-5]. She received treatment via oral medication at a medical institution. In many cases, the subjects did not inform their doctors about their use of health foods, including Pueraria mirifica.
Table 1: Subject Attributes ( $\mathrm{n}=14)$.

\begin{tabular}{|c|c|c|c|}
\hline & & $\mathbf{n}$ & $\%$ \\
\hline Sex & Female & 14 & $(100.0)$ \\
\hline Education & High school & 43.4 years & \\
\hline & $\begin{array}{c}\text { Technical college/college of } \\
\text { technology }\end{array}$ & 7 & $(21.4)$ \\
\hline & $\begin{array}{c}\text { Universities and graduate } \\
\text { schools }\end{array}$ & 4 & $(50.0)$ \\
\hline Marital status & Married & 6 & $(42.9)$ \\
\hline Work & Employed & 11 & $(78.6)$ \\
\hline $\begin{array}{c}\text { Health } \\
\text { condition }\end{array}$ & $\begin{array}{c}\text { Very healthy } \\
\text { Somewhat healthy }\end{array}$ & 2 & $(14.3)$ \\
\hline & Normal & 5 & $(42.9)$ \\
\hline & Not very healthy & 1 & $(7.1)$ \\
\hline \multicolumn{2}{|c|}{ Not healthy at all } & 0 & $(0.0)$ \\
\hline & Excluding missing/no answer & & \\
\hline
\end{tabular}

\section{Motives for Buying Pueraria Mirifica}

Many of the motives for purchasing Pueraria mirifica involved the subjects' unhappiness with their breasts. Others purchased it expecting beneficial effects for the skin, for weight loss, or because they thought it was for women.

'I heard that some people started to have periods again after menopause.'

'I only want to maintain how I am now in order to be prepared for getting old.'

'My breasts became saggy after giving birth and breast feeding, and I wanted to get back the fullness.'

The internet (official website, blogs, or Instagram) and wordof-mouth were the sources of information in many cases. Search keywords included "pueraria", "breast enhancement", "big boobs", "supplements", and "breast-enlarging", and the subjects purchased the product online due to the high cost of treatment at medical institutions. Some of them purchased the product based on the information promoted via "\#Pueraria” on Instagram.

'There were pictures of several people before and after using the product.'

'It was introduced in an entertainment show on TV.'

Specific products were often sold in a bottle with a fancy illustration or in a pouch with a pink label, which was often printed with words such as "marshmallow", "popular with men", "love", or "feminine" [6,7].

'There is no need to worry if the product is manufactured by a large supplement company in Japan.' 
"The words "very popular and limited" always attract me and make me buy.'

The subjects said that they chose a product with a price that matched the expected effects and purchased it considering the cost-effectiveness. The cost ranged from 2,000 yen to 9,000 yen per month in most cases; however, in one case, the product was purchased in instalments of several hundred thousand yen. The prices and the product contents varied; some purchased the supplements alone, a set of supplements and gels, or an advisor in addition to a gel and supplement set. There were subjects who made single purchases because they were wary of subscriptions that are inexpensive upfront but later require multiple purchases. It was also mentioned that Pueraria mirifica is frequently used by women, such as models and nightclub hostesses, whose occupations require them to have beautiful bodies [7].

'Back then, I was working in a nightclub, and a person I knew of was importing health foods privately in bulk. Those, including pueraria, were shared among us, and we all took it.'

\section{Information Source and the Site from which the Product}

\section{Name was Learned}

In most cases, the subjects searched and purchased the products on Amazon or Rakuten, saw the products on e-newsletters or advertisements from online shops they normally used, or looked them up on the Japanese version of Yahoo Answers. Others heard from friends about the stores from which they purchased the health food product.

'I was worried whether it would have the effects as advertised online.'

\section{'I purchased it without expecting too much.'}

'I felt I was losing my figure, and I was going through the stage where people are inclined to take something like supplements.'

'I purchased it based on the images that showed that it is a natural herb, made from plant roots from Thailand, and rich in female hormones.'

I admired celebrities with good figures, and I was undergoing placenta therapy and cosmetic surgery and going to an Indian-style spa.'

\section{Reasons for Use other than to get in Shape}

Subjects used the product for reasons beyond breast enhancement; some expected the products to result in beautiful, smooth, perky skin $[2,8,9]$.

\section{Confirmation of the Reputation before Purchase}

Many study participants referenced reviews on Amazon and Rakuten. They also referenced the Japanese version of Yahoo Answers, the beauty-related bulletin board on 2channel (a Japanese online forum), and blogs specialized in supplements.

\section{Reasons for not Visiting a Medical Institution}

Many participants said they sought an affordable health food because going to a doctor's office would have been expensive. Moreover, health foods were used as an easy fix because the subjects' health concerns were not serious enough to warrant a trip to a medical institution. Psychological resistance to seeing a doctor for such reasons was also mentioned. In addition, several participants said they took supplements and health foods to make themselves beautiful "from inside of the body" [10].

'Beauty salon treats the outside of the body, but I wanted to be beautiful from inside. The methods I could do easily by myself instead of going to a medical institution were to take supplements and health foods.'

\section{Health Damages and Symptoms and How they were Handled}

One study participant decided to see a doctor and cancelled the health food policy due to changes in her health condition, femalehormone-associated health damage, and menstrual irregularity. In addition, there were some cases in which irregular menstrual periods were corrected and became regular, the breasts became firm (some took this as a positive effect and others as a negative), and menstrual periods stopped. A slight fever, headache, and discomfort were also reported. In some cases, the participants visited a medical institution for these symptoms, stopped taking supplements, and were treated with hormone therapy [11-13].

\section{Warning sentence included in Advertisements}

Many of the study participants were not aware of the warnings associated with Pueraria mirifica use. However, in some cases, that participants recognized the warnings and still used the products; they accepted some side effects or did not think that those side effects were likely to occur.

'I had seen the warning but thought it would be fine if the adverse effects are not significant since drugs and health foods have some side effects, and I did not take it seriously.'

\section{Alerts from the Consumer Affairs Agency and the Ministry of Health, Labour, and Welfare}

When the investigator informed the study participants who did not know of the alert about Pueraria mirifica, they regretted that it was dangerous because they planned to get pregnant and give birth in the future. After seeing the warnings issued by the Japan Medical Association, some participants were convinced that the changes in health condition (both good and bad) they had experienced were due to the health food. Some cancelled their subscriptions. In one case, the participant had taken Pueraria mirifica more than 10 years prior; she said there were no official warnings at that time.

'Because I was taking pueraria, my child could have been exposed to danger. I am so relieved that nothing happened to my child.' 


\section{Intentions of Continued Product Use}

Despite being aware of the alerts, some said they might switch to a different product that does not contain Pueraria mirifica or might continue using Pueraria mirifica if there are beneficial effects that outweigh the adverse effects. While one participant recognized the alerts, she said she still hoped for the breast enhancing effects, had exchanged information with her friends, and was already thinking of purchasing the next similar product. One participant who had subscribed to a regular supply of Pueraria mirifica cancelled it after becoming aware of the alert.

I was casually taking it thinking that there would not be many side effects as it is a supplement, but I decided not to rely on supplements.'

I chose this company for its sophisticated website and modest advertisement, but I felt it was risky after looking at it closely, as the company sells dangerous products.'

\section{Other}

Some subjects mentioned that a health-food company assigned individual advisors and provided an organized, long-term support and consultation system $[11,13]$.

'I think it is better to tell the doctor about taking the health foods. But I get various advice and consultation through the helpful support by the health food company. I was encouraged to talk to them if I had a reason for cancellation and if my menstrual periods become irregular.'

\section{Discussion}

Clarifying the factors surrounding use of health foods such as Pueraria mirifica is expected to reveal an effective way to provide information on health foods and aid in the prevention of health damage. Pueraria mirifica is a health food/supplement that speaks to women's desire to be beautiful. Soft-coloured packaging, modern websites, and before and after photos are effective advertisements for the products. However, online information may not convey accurate information regarding a product's effects and safety; with current digital technology, photographs can be easily edited and modified, and consumers are often led by blogs or product reviews. The internet has facilitated the dissemination of information on health foods and supplements, but unreliable information exists. The need for dissemination of correct information was indicated at the "Integrated Medicine Study Committee" meeting hosted by the Ministry of Health, Labour, and Welfare [2], and the evidence-based Japanese Integrative Medicine (eJIM) has been established [3]. In addition, the latest information on the safety and effectiveness of health foods is provided on the HF Net . Good Manufacturing Practice (GMP) guidelines have been developed to encourage businesses to voluntarily comply [3].
Therefore, consumers need access not only to online reviews and information from the seller but also to the above-mentioned reliable information. They should critically judge all information before carefully making a purchase [3]. The government needs to establish a support system for individuals seeking health foods through health education and information provisions. This study was limited in that it included only subjects living in the Kanto area and that the surveyed opinions were limited to those of females, even though there were males who also purchased the products. Therefore, the generalization of the results requires careful attention. Furthermore, the study included not only those who had purchased and were ingesting Pueraria mirifica but also those who did so 10 years prior. Therefore, our data may include errors of memory, and a more rigorous, large-scale survey is required [10]. The factors surrounding the usage of particularly dangerous health foods have yet to be grasped. As the government seeks to provide appropriate information to the public, physicians, and healthcare professionals, our findings may help build a foundation for the safe use of health foods.

\section{Conclusion}

Many study participants purchased Pueraria mirifica for beauty purposes such as breast enhancement or skin beautification. They purchased products that appeared to be effective and affordable based on online reviews and the impressions provided by sales companies. However, in one case, the expected effects were not seen and health troubles, such as irregular menstrual periods, occurred and required medical attention. Although about half of the study participants knew about the alert issued by the Customer Affairs Agency and the Ministry of Health, Labour, and Welfare, many were not aware of it at the time of purchase. A purchasing pattern was revealed in which consumers search and examine the effects of the product online, purchase the product unaware of the public alert, and, after the purchase, stop taking the product due to development of a poor physical condition or after being informed of the alert. From the above, it is necessary to improve the methods of information dissemination, such as search engine optimization, so that alert information can reach consumers before they make their purchases. Preferably, consumers would have access to the alert information at the same time as they access the product reviews, enabling them to make sound judgments. It would also be wise to establish a system to communicate information to professionals in the event of health damage.

\section{Acknowledgements}

The authors would like to thank the participants of the study. This work was supported by the MHLW Grant for Scientific Research (Food Safety Promotion Research Project) "Research to address technical issues necessary for ensuring the safety of health foods and to effectively disseminate information" (Representative: 
Hitoshi Fujii). In addition, written informed consent was obtained from all participants.

\section{References}

1. Kreijkamp Kaspers S, Kok L, Grobbee DE, De Haan EHF, Aleman A, et al. (2004) Effect of Soy Protein Containing Isoflavones on Cognitive Function, Bone Mineral Density, and Plasma Lipids in Postmenopausal Women: A Randomized, Controlled Trial. JAMA 292: 65-74.

2. Jiang RW, Lau KM, Lam HM, Yam WS, Leung LK, et al. (2005) A comparative study on aqueous root extracts of Pueraria thomsonii and Pueraria lobata by antioxidant assay and HPLC fingerprint analysis. Journal of Ethnopharmacology 96(1-2): 133-138.

3. Kongkaew C, Scholfield NC, Dhippayom T, Dilokthornsakul P, Saokaew S, et al. (2018) Efficacy and safety of Pueraria candollei var. mirifica (Airy Shaw \& Suvat.) Niyomdham for menopausal women: A systematic review of clinical trials and the way forward. J Ethnopharmacol 216: 162-174.

4. (2020) Japan Medical Association. Please be careful with the use of health foods including "Pueraria mirifica."

5. (2020) Ministry of Health, Labour and Welfare. "Health foods" containing Pueraria mirifica"

ISSN: 2574-1241

DOI: 10.26717/BJSTR.2020.32.005315

Keiko Yukawa. Biomed J Sci \& Tech Res

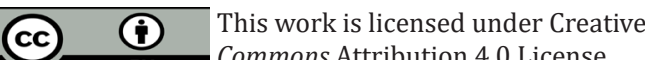

Submission Link: https://biomedres.us/submit-manuscript.php
6. Yamada K, Onozawa Y, Nagata E, Ichinohe K, Morita T, et al. (2018) "Health foods" containing Pueraria mirifica as a raw material. Food sanitation research 68(3): 15-23.

7. (2020) Seikatsu Kojo Web. Inc.

8. Lofland J, Lofland L (1997) Analyzing social settings: a guide to qualitative observation and analysis. Translated by Shindo Y, Hogetsu M (Eds.)., Kouseisha-kouseikaku Corporation, Tokyo, Japan, pp. 244-276.

9. (2020) Ministry of Health, Labour and Welfare. Study Group on how "Integrated Medicine" should be.

10. (2020) Ministry of Health, Labour and Welfare. The Evidence-based Japanese Integrative Medicine (eJIM).

11. (2020) National Institute of Health and Nutrition. Information of safety and efficacy of "health foods."

12. GMP (Good Manufacturing Practice) guidelines.

13. (2020) Ministry of Health, Labour and Welfare. The Evidence-based Japanese Integrative Medicine (eJIM). How to determine which information is credible.

$\begin{array}{ll}\text { BIOMEDICAL } & \text { Assets of Publishing with us } \\ \text { RESEARCHES } & \text { - Global archiving of articles } \\ \text { - Immediate, unrestricted online access }\end{array}$

